\title{
Studies on non-traditional oils: I. Detailed studies on different lipid profiles of some Rosaceae kernel oils
}

\author{
By Minar M. M. Hassanein \\ National Research Centre, Fats and Oils Res. Dept. Dokki, Cairo, Egypt.
}

\section{RESUMEN}

Estudios de aceites no tradicionales: I. Estudios detallados sobre diferentes perfiles lipídicos de aceites de semillas de la familia Rosaceae.

Aceites obtenidos de las semillas de albaricoque, melocotón y ciruela, producidos como subproductos de la industria alimenticia conservera, se analizaron mediante cromatografía gaseosa capilar y cromatografía líquida de alta resolución. Se estableció la composición en ácidos grasos de los mono-, di- y triacilgliceroles fraccionados. El ácido oleico osciló desde el $64 \%$ al $72 \%$ en triacilgliceroles (TAG), mientras que el ácido linoleico lo hizo entre el $17 \%$ y el $27 \%$. El perfil de TAG mostró la presencia de OOO (35-42\%), LOO (22-28\%), LLO (7-16\%), LOP y LLS (6-7\%), OOP (6-10.4\%). En los tres aceites analizados se detectaron campesterol-, 5 -estigmasterol-, $\beta$-sitosterol-, isofucosterol, 7-estigmasterol y avenasterol. También se determinaron glicósidos de esteroles, mostrando perfiles característicos. El contenido en tocoferoles fue apreciable en todos ellos, siendo el gamma-tocoferol el predominante. Los alfa- y delta-tocoferoles se detectaron en pequeñas cantidades. Los resultados obtenidos pueden usarse para caracterizar estos aceites de semilla y facilitar su diferenciación de otros aceites.

PALABRAS-CLAVE: Aceite de semilla de albaricoque - Aceite de semilla de ciruela - Aceite de semilla de melocotón - Perfil lipídico.

\section{SUMMARY}

Studies on non-traditional oils: I. Detailed studies on different lipid profiles of some Rosaceae kernel oils.

Kernel oils obtained from apricot, peach and plum, produced as by-products from food canning industry, were analyzed by capillary $\mathrm{GC}$ and HPLC. The fatty acid composition of the fractionated mono-, di- and triacylglycerol was elucidated. Oleic acid ranged from 64 to $72 \%$ in triacylglycerol (TAG), whereas linoleic acid ranged from $17 \%$ to $27 \%$. The TAG profile showed the presence of OOO $(35-42 \%)$, LOO (22-28\%), LLO (7-16\%), LOP and LLS (6-7\%), OOP (6-10.4\%). Campesterol-, 5 -stigmasterol-, $\beta$-sitosterol-. isofucosterol, 7 -stigmasterol and avenasterol were detected in the three analyzed oils. Sterylglycosides were also determined and showed some characteristic profiles. The three kernel oils contained appreciable amounts of tocopherols in which gamma-tocopherol was the predominating one. Alpha-and delta-tocopherols were also present in smaller quantities. Results obtained can be used to characterize these kernel oils and facilitate their differentiation from the other oils.

KEY-WORDS: Apricot seed oil - Lipid profile - Peach seed oil Plum seed oil.

\section{INTRODUCTION}

Kernels of apricot, peach and plum, belonging to the family Rosaceae, are produced as by-products in tonnages from food canning industry (1). The kernels are considered as non-traditional potential resources for oils (2).

Previous studies on some Rosaceae kernel oils had been reported by some authors $(2,3,4,5,6,7)$ determining some minor component fatty acids and fatty acid constituents of phospholipids and glycolipids. These oils contained appreciable amounts of oleic and linoleic acids, however linolenic acid was found to be negligibly present.

Tonnages of kernels of peach, apricot and plum are produced from the local food canning industry and their oils have not been fully studied. Peach and apricot kernel oils of the locally cultivated varieties, have been studied by some authors $(6,7)$. Apricot and peach kernel oils had been analyzed only for their fatty acids (6) whereas peach kernel oil had been investigated for their fatty acid and sterol composition (7). Kernel oils of peach and apricot have been used as adulterants or substitutes for some expensive oils particularly, almond oil (8). Therefore, there is a lack of data on the composition of the different lipids of these kernel oils. The objective of this work was to elucidate their fatty acid, triacylglycerol, sterol, sterylglycoside and tocopherol patterns using advanced methods of analysis in order to characterize and possibly to differentiate Rosaceae kernel oils from other vegetable oils.

\section{MATERIALS AND METHODS}

\subsection{Materials}

Plum (Prunus domestica), apricot (Prunus armeniaca) and peach (Prunus persica) kernels were obtained from food canning factories, (season 1997) cleaned and dried at $100^{\circ} \mathrm{C}$ for $10-12 \mathrm{hrs}$. The oil was extracted with chloroform-methanol $(2 / 1 \mathrm{v} / \mathrm{v})$ and the oil content was calculated on dry basis (9). 


\subsection{Methods}

\subsubsection{Oil fractionation and fatty acid composition}

\subsubsection{Chromatographic fractionation of oil}

The oil was fractionated into triacylglycerol (TAG) (the predominating fraction) and the minor diacylglycerol (DAG) and monoacylglycerol (MAG) as well as free fatty acids (FFA). Fractionation was conducted with the help of thin-layer chromatography (TLC) using hexane/diethyl ether/formic acid $(70 / 30 / 1 \mathrm{v} / \mathrm{v} / \mathrm{v})$ as developing solvent. The located zones of TAG $\left(R_{f}=0.76\right)$, DAG $\left(R_{f}=0.15\right)$, MAG $\left(R_{f}=0.01\right)$ and FFA $\left(R_{f}=0.4\right)$ were scraped from the plate and extracted with moistened $n$-hexane at $50^{\circ} \mathrm{C}$. The hexane solution was dried over anhydrous sodium sulphate and the solvent was distilled off under $\mathrm{N}_{2}$.

\subsubsection{Preparation of methyl esters}

Each fraction was converted into methyl esters using $5 \% \mathrm{HCl}$ in methanol and the mixture was refluxed at $70-80{ }^{\circ} \mathrm{C}$ for two hours till complete transesterification (10). The reaction was monitored with the help of TLC to ensure the conversion of all MAG, DAG or FFA into methyl esters. TLC was carried out using glass plates $(20 \times 20 \mathrm{~cm})$ coated with $0.25 \mathrm{~mm}$ layer of silica gel G (Merk) and was developed with $\mathrm{n}$-hexane : diethyl ether : acetic acid $(80: 20: 1 \mathrm{v} / \mathrm{v} / \mathrm{v})$. The dry plates were subjected to iodine vapour to detect the formed methyl esters and the progress of methylation reaction. After the termination of the reaction, the reaction mixture was transferred to a separating funnel containing diethyl ether to extract the methyl esters. The ether layer was thoroughly washed with distilled water till neutrality and the solution was dried over anhydrous sodium sulphate and filtered. The ether was evaporated under reduced pressure at room temperature using a rotary evaporator apparatus. The methyl esters were placed in $5 \mathrm{ml}$ vials and stored until use at $10^{\circ} \mathrm{C}$.

\subsubsection{GLC analysis of fatty acid methyl esters}

Hewlett-Packard HP 5890-A instrument was used for the analysis of the fatty acid methyl esters. All analysis were conducted by temperature programming using an efficient capillary column under the following operating conditions: column: $0.32 \mathrm{~mm} \times 30 \mathrm{~m}$ filled with DB-23 (film thickness, 0.25 $\mu \mathrm{m})$; column temperature: $150 \sim 230{ }^{\circ} \mathrm{C}, 3.0^{\circ} \mathrm{C} / \mathrm{min}$ injector temperature: $230{ }^{\circ} \mathrm{C}$; detector: flame ionization (FID); carrier gas: $\mathrm{N}_{2}$, flow rate, $1.3 \mathrm{ml} / \mathrm{min}$ and split ratio (100:1). Peaks areas were determined by electronic integrator and percentage composition of fatty acids was automatically calculated. Standard mixture of fatty acids were similarly chromatographed.

\subsubsection{Triacylglycerol}

HPLC (Tosoh, Japan) was used for the direct analysis of triacylglycerol $(11,12) ; 10 \mu$ oil in chloroform $(300 \mathrm{mg} / \mathrm{ml})$ was injected under the following conditions: column ODS capcel Pak $\mathrm{C}_{18}$ $(4.4 \times 100 \mathrm{~mm})$; gradient elution with acetonitrile: dichloromethane (starting from 90:10 to $35: 65, \mathrm{v} / \mathrm{v}$ in $150 \mathrm{~min}$ ); detector, FID (with moving band, tracor 945).

\subsubsection{Sterols}

Sterols were isolated from the unsaponifiables via preparative silica gel $G$ plates using chloroform: diethyl ether: acetic acid $(95: 4: 1, \mathrm{v} / \mathrm{v} / \mathrm{v})$. The isolated sterol mixtures were treated with silylating reagent consisting of three parts of hexamethyl disilazane (HMDS) and one part of trimethyl-chlorosilane (TMCS) with 10 parts of dry pyridine as a solvent. After a reaction period of about $15 \mathrm{~min}$ at room temperature, the mixture was directly injected into gas chromatograph (Hewlett-Packard-HP 5890-A). The analysis was conducted under the following operating conditions : column; DB-17 (0.32 mm x 15 $\mathrm{m}$ with $0.25 \mu \mathrm{m}$ coating) at $250^{\circ} \mathrm{C}$; detector, FID at $260{ }^{\circ} \mathrm{C}$; carrier gas, Helium $(8.6 \mathrm{ml} / \mathrm{min})$ and split ratio $35: 1$. The \% peak areas were calculated by electronic integrator $(10,13)$.

\subsubsection{Free and acylated sterylglycosides}

The oil sample in chloroform was injected into silica gel cartridge (Sep-Pak, Waters) and the mixed sterylglycosides were eluted with chloroform: methanol $(1: 1, \mathrm{v} / \mathrm{v})$. The eluted compounds were fractionated with the help of preparative TLC using chloroform: methanol: formic acid (90:15:1, v/v/v) into free sterylglycoside (FSG) and acylated sterylglycoside (ASG). Only ASG was deacylated with alkaline hydrolysis $(0.5 \mathrm{~N} \mathrm{KOH}$ in isopropanol) to obtain FSG. The obtained FSG and the original one were separately converted into their 1-anthroyInitrile derivatives (SG-1-AN).

HPLC was used for the analysis of SG-1-AN under the following conditions: column, ODS Wakosil-5, $\mathrm{C}_{18}(6.4 \times 250 \mathrm{~mm})$; elution: gradient using acetonitrile: dichloromethane (from 50:50 to 68:32, v/v); detector: UV and absorption was measured at $254 \mathrm{~nm}$ (14). 


\subsubsection{Tocopherols}

HPLC (Tosoh) was used for direct analysis of tocopherols. A sample of $10 \mu \mathrm{l}$ oil in $\mathrm{n}$-hexane $(10 \%$ soln.) was injected in HPLC column (silica, YMCA-012, $6.2 \times 150 \mathrm{~mm}$ ). Elution was isocratic using n-hexane:isopropyl alcohol (100: $0.5, \mathrm{v} / \mathrm{v})$ at flow rate $2 \mathrm{ml} / \mathrm{min}$. Hitachi-650-10S fluorescence detector was used. Spectral absorption was set at excitation and emission wave lengths 295 and $325 \mathrm{~nm}$ (13).

\section{RESULTS AND DISCUSSION}

Dry kernels of plum, apricot and peach contained $32 \%, 37 \%$ and $43 \%$ of oil respectively. Therefore, these kernels could be used as potential sources of oils.

\subsection{Fatty acid pattern}

Table I shows that triacylglycerol (TAG) of peach kernel oil contain lower concentration of palmitic acid compared to those of apricot and plum, whereas apricot kernel oil contains comparatively higher percentage oleic acid $(n-9)$ than the other two oils. Stearic acid in apricot is generally higher than that in plum and peach. Linoleic acid in peach kernel oil is higher than that in the other two oils.

Table I

Fatty acid composition of the fractionated glycerides of the three Rosaceae kernel oils determined by GLC

\begin{tabular}{|c|c|c|c|c|c|c|c|c|c|c|}
\hline \multirow[b]{2}{*}{ Sample } & \multirow[b]{2}{*}{ Content (\%) } & \multicolumn{9}{|c|}{ Fatty acid composition (\%) } \\
\hline & & $16: 0$ & $16: 1$ & $18: 0$ & $\begin{array}{c}18: 1 \\
n-9\end{array}$ & $\begin{array}{c}18: 1 \\
n-7\end{array}$ & $18: 2$ & $18: 3$ & $20: 0$ & $20: 1$ \\
\hline \multicolumn{11}{|l|}{ Plum } \\
\hline TAG & 99.1 & 6.0 & 0.6 & 2.2 & 69.4 & 1.1 & 20.4 & & 0.2 & 0.1 \\
\hline DAG & 0.5 & 7.7 & - & 3.2 & 63.9 & 1.6 & 23.6 & & - & - \\
\hline MAG & tr. & - & - & - & - & - & - & & - & - \\
\hline FFA & 0.4 & 18.9 & - & 6.7 & 54.8 & - & 19.6 & & - & - \\
\hline \multicolumn{11}{|c|}{ Apricot } \\
\hline TAG & 99.1 & 5.8 & 0.4 & 2.7 & 72.1 & 0.9 & 17.8 & & 0.2 & 0.1 \\
\hline DAG & 0.6 & 10.2 & - & 3.2 & 62.7 & 1.7 & 22.2 & & - & - \\
\hline MAG & tr. & - & - & - & - & - & - & & - & - \\
\hline FFA & 0.3 & 20.6 & - & 7.9 & 55.2 & - & 16.3 & & - & - \\
\hline \multicolumn{11}{|l|}{ Peach } \\
\hline TAG & 99.3 & 4.6 & 0.6 & 1.3 & 64.5 & 1.4 & 27.3 & 0.1 & 0.1 & 0.1 \\
\hline DAG & 0.3 & 5.5 & - & 1.5 & 59.5 & 2.0 & 31.5 & - & - & - \\
\hline MAG & tr. & - & - & - & - & - & - & - & - & - \\
\hline FFA & 0.4 & 12.9 & - & 4.1 & 57.1 & - & 25.9 & - & - & - \\
\hline
\end{tabular}

TAG: Triacylglycerol

DAG: Diacylglycerol

MAG: Monoacylglycerol

FFA: Free fatty acids

In diacylglycerol (DAG) fraction, apricot kernel oil contains higher percentage of palmitic acid than those in the other two oils. On the other hand, the DAG fraction in plum kernel oil contains slightly higher content of oleic acid, whereas DAG in peach kernel oil contains higher amount of linoleic acid than the corresponding fraction in the other two kernel oils.

MAG fraction is found in trace amount in the three kernel oils (Table I). Palmitic, stearic, oleic and linoleic acid were detected in appreciable amounts in the free form.

\subsection{Triacylglycerol pattern}

Eleven TAG molecular species were determined in the three kernel oils, at various amounts (Table II). Kernel oils, were free of linolenate $(X)$, no TAGs including this acid were detected. LLL, in peach kernel oil is in higher percentage than the other two oils. LLO constitutes $16.0 \%$ in peach kernel oil which is markedly higher than that in plum $(9.6 \%)$ and apricot $(7.6 \%)$. LOO is the major TAG component of the three kernel oils, but peach contains higher 
percentage $(28.5 \%)$ than that in plum kernel oil $(23.9 \%)$ and apricot kernel oil $(22.0 \%)$. LLS is incompletely separated from LOP and the two peaks were calculated as one. Thus, the LLS-LOP constitute $7.1,6.9$ and $6.3 \%$ for plum, apricot and peach, respectively. $\mathrm{OOO}$ is the second major TAG component that amounts to $42.9,43.8$ and $35.6 \%$ in plum, apricot and peach respectively, showing a comparatively lower amount in peach kernel oil. In apricot kernel oil, OOP is higher $(10.4 \%)$ than that in plum $(8.6 \%)$ and peach kernel oil $(6.0 \%)$, whereas, OOS is present at levels of $3.1,4.6$ and $1.4 \%$ in plum, apricot and peach kernel oils, respectively.

It seems that each oil exhibits very characteristic TAG pattern that can differentiate one oil from the other. Thus, peach exhibits higher LLL, LLO, LOO and lower $\mathrm{OOO}$, whereas apricot shows a markedly higher amount of OOP.

Table II

Triacylglycerol profiles of the three Rosaceae kernel oils determined by HPLC

\begin{tabular}{cccc}
\hline Molecule species & Plum & Apricot & Peach \\
\hline LLL & 1.4 & 1.1 & 3.1 \\
LLO & 9.6 & 7.6 & 16.0 \\
LLP & 1.5 & 1.0 & 1.6 \\
LOO & 23.9 & 22.0 & 28.5 \\
LLS & 7.1 & 6.9 & 6.3 \\
LOP & 0.2 & 0.2 & 0.2 \\
OPP & 42.9 & 43.8 & 35.6 \\
LOS & 1.5 & 2.2 & 1.2 \\
OOP & 8.6 & 10.4 & 6.0 \\
POP & 0.2 & 0.2 & 0.1 \\
OOS & 3.1 & 4.6 & 1.4 \\
\hline
\end{tabular}

$X:$ Linolenic

L: Linoleic

O: Oleic

P: Palmitic

S: Stearic

\subsection{Tocopherols pattern}

Tocopherol content of plum kernel oil was distinctly higher than that of apricot and peach kernel oils (Table III). Plum, apricot and peach kernel oils contained 710,430 and 520 ppm respectively. These oils were rich in gamma-tocopherol containing $85.5 \%, 93.5 \%$ and $97.7 \%$ respectively. However, alpha-and delta-tocopherols were detected in minor amounts. Beta-tocopherol was not detected in the three oils. Based on the tocopherol patterns of the three kernel oils, it can be denoted that these three oils are highly resistant to autoxidation due to the presence of gamma-tocopherol in high percentage. The later exhibits high antioxidant activity (15).

\subsection{Sterols pattern}

GLC analysis of the sterol's TMS using capillary column gives different sterol patterns for the three kernel oils (Table IV). Plum kernel oil contained higher amount of campesterol compared to the other two kernel oils. However 7-stigmasterol was detected in apricot kernel oil at a concentration of $1.8 \%$ which was higher than that in peach kernel oil $(1.0 \%)$. In plum kernel oil it was detected in trace amount. Peach kernel oil contained comparatively higher amount of isofucosterol than the other two oils. Therefore, the three oils can be differentiated one from the other by the higher campesterol content in plum kernel oil, the higher 7-stigmasterol in apricot and finally the higher isofucosterol in peach kernel oil.

\subsection{Sterylglycoside profiles of FSG and ASG}

Sterylglycosides were present in the kernel oils as non esterified (FSG) and esterified (ASG) forms (Table V). The total amounts of these compounds was 150,170 and $155 \mathrm{ppm}$ for plum, apricot and peach kernel oils respectively. The FSG fractions of the kernel oils were present at lower levels than that of the ASG. Only apricot kernel oil contained $0.6 \%$ avena-SG and 3.5\% 7-stigma-SG which is unique in this respect (Table V). In plum kernel oil, isofuco-SG and campe/stigma-SG were determined in higher concentrations than in the other two oils. Peach kernel oil showed SG patterns of FSG with lower amount of campe-/stigma-SG than the other two oils.Peach kernel oil showed SG patterns of FSG with lower amount of campe-/stigma-SG than the other two oils. Therefore, the FSG patterns of the three oils can be used for their differentiation. The ASG fraction of plum, apricot and peach kernel oils was 131,129 and 104 ppm respectively. In FSG and ASG fractions of plum kernel oil, the isofuco-SG and campe-/stigma-SG were present in higher amounts than in the other two kernel oils. It should be noted that SG's, as minor lipid components, have received the interest of some authors $(13,14,16)$. They seem to be sterol carriers in plant tissue of the seeds (17). According to our findings, SG patterns of the three kernel oils are more decisive for differentiating and recognizing these three kernel oils. 
Table III

Tocopherol composition of the three Rosaceae kernel oils determined by HPLC

\begin{tabular}{|c|c|c|c|c|c|}
\hline \multirow{2}{*}{ Sample } & \multirow{2}{*}{ Total ppm } & \multicolumn{4}{|c|}{ Tocopherol composition (\%) } \\
\hline & & Alpha-Tocopherol & Beta-Tocopherol & Gamma-Tocopherol & Delta-Tocopherol \\
\hline Plum & 710 & 11.0 & - & 85.5 & 3.5 \\
\hline Apricot & 430 & 5.0 & - & 93.5 & 1.5 \\
\hline Peach & 520 & Trace & - & 97.7 & 2.3 \\
\hline
\end{tabular}

Table IV

Sterol patterns of the three Rosaceae kernel oils determined by GLC

\begin{tabular}{ccccccccc}
\hline & & \multicolumn{5}{c}{ Sterol composition (\%) } \\
\cline { 3 - 8 } Sample & Content (\%) & Campesterol & Stigmasterol & B-sitosterol & Isofucosterol & 7-stigmasterol & Avenasterol \\
\hline Plum & 0.32 & 5.5 & 0.9 & 87.4 & 6.2 & Trace & - \\
Apricot & 0.35 & 4.0 & 0.9 & 87.8 & 5.5 & 1.8 & - & - \\
Peach & 0.37 & 4.1 & - & 84.4 & 10.5 & 1.0 & - \\
\hline
\end{tabular}

Table V

Sterylglycoside profiles of the three Rosaceae kernel oils determined by HPLC

\begin{tabular}{|c|c|c|c|c|c|c|c|}
\hline \multirow{2}{*}{ Sample } & \multirow{2}{*}{ SG type } & \multirow{2}{*}{ Content ppm } & \multicolumn{5}{|c|}{ Sterylglycoside composition (\%) } \\
\hline & & & Avena-SG & Isofuco-SG & Campe/stigma-SG & 7-stigma-SG & B-sito-SG \\
\hline \multirow{2}{*}{ Plum } & FSG & 19 & - & 6.0 & 3.9 & - & 90.1 \\
\hline & ASG & 131 & - & 4.8 & 4.0 & - & 91.2 \\
\hline \multirow{2}{*}{ Apricot } & FSG & 41 & 0.6 & 4.7 & 2.5 & 3.5 & 88.7 \\
\hline & ASG & 129 & - & 2.9 & 2.8 & - & 94.3 \\
\hline \multirow{2}{*}{ Peach } & FSG & 51 & - & 4.4 & 1.9 & - & 93.7 \\
\hline & ASG & 104 & - & 3.3 & 2.9 & - & 93.8 \\
\hline
\end{tabular}

SG: Sterylglycoside

FSG: Free sterylglycoside

ASG: Acylated sterylglycoside

In the light of the different lipid compositions of the three Rosaceae oils in comparison with some common oils, the following observation can be pointed out:

Rosaceae oil TAG are rich in oleic acid which ranges from 64.5 to $72.1 \%$. They also contain linoleic acid at amounts similar to that in rape seed oil, however cottonseed and sunflower oils contain appreciably higher amounts of linoleic acid $(17,18)$.

Concerning the TAG profiles, $\mathrm{OOO}$ is the predominating TAG in the three Rosaceae oils, however cottonseed, sunflower oils contain very lower amounts, whereas rapeseed contains reasonable amounts. On the other side, LLL in these three kernel oils is lower than in cottonseed and sunflower oils, whereas rapeseed oil contains very little amount of this TAG. LOP in the three kernel oils is present in amounts lower than in cottonseed and sunflower oils but is similar to that of rapeseed $(17,18)$.

The three kernel oils show very characteristic tocopherol patterns in which gamma-tocopherol is the predominating one. On the other side, the common seed oils are either rich in alpha-tocopherol (sunflower) or in gamma-tocopherol (corn oil). However, in cottonseed and rapeseed oil the ratios of alpha to gamma-tocopherol are $1: 1$ and 1:5 respectively (17).

7-Stigmasterol is generally present in lower amounts in apricot, peach and plum kernel oils respectively in comparison to sunflower oil (17). The 
presences of characteristic sterol in common oils can help differentiate them from Rosaceae oil.

In contrast to some common seed oils (cottonseed and rapeseed oils), Rosaceae kernel oils are characterized by having low total sterylglycoside contents. In addition, free sterylglycosides of the kernel oils are present in comparatively lower levels than those of the acylated ones, which is not the case with the two common oils (17).

It can be concluded that from the different lipid profiles of the analyzed Rosaceae oils, it is possible to detect any one of them, if it is mixed with other oil. Particularly apricot and peach oils are sold as adultrants or substitutes for almond oil.

\section{ACKNOWLEDGEMENT}

The author wishes to thank Prof. Dr. M. Hassan El-Mallah and Prof. Dr. S. El-Shami of National Research Centre for their advice and criticism.

\section{REFERENCES}

1. Egyptian Food Industries Organization (1998).

2. Banerjee, R. and Subrahmanyam, V. V. R. (1985)."Composition and Characteristics of a Few Potential Oils».-ISF-OTAI Congress. 17th World Congress of the International Society for Fat Research, New Delhi, India February, 18-19.

3. El-Khalafy, H. M., Gad, A. M., Hassan, M. M. and Shoeb, Z. E. (1968).- «Chemical Constitution of Some Rosaceae Solanaceae and Oleaceae Seed Oils".-Grasas y Aceites, 19, 139-142.

4. Khotpal, R. R., Kulkarni, A. S. and Bhakare, H. A (1985). - «Studies on Phospholipid Composition of Some Non-Traditional Seeds: Fatty Acid Composition of their Total Phospholipids».-ISF-OTAI Congress 17th World Congress of the International Society for Fat Research, New Delhi, India February, 16-17.

5. Khotpal, R. R., Kulkarni, A. S. and Bhakare, H.A.«Studies on the Glycolipid Composition of Non-Traditional Seeds: Fatty Acid Composition of their Total Glycolipids».--lbid, 17-18.

6. Helmy, H. E. and Shoeb, Z. E.(1991)._-Utilizing Apricot and Peach Kernel Oils in Preparation of Fine
Grade Soaps».-Seifen-Ole-Fette. Wachse, 117, (7) 257-258.

7. Saadany, R. M. A. El., Kalaf, H. H. and Soliman, M. (1993). - «Characterization of Lipids Extracted from Peach Kernels".-Crops, 1, 123-127.

8. Egan, H., Ronald, K. S. and Ronald, S. (1981)."Pearson's Chemical Analysis of Foods".-Eighth Edn. Churchill, Livingstone Edinburgh London Melboume and New York, 507-547.

9. Gopalakrishnan, N., Kaimal, T. N. B. and Lakshminarayana, G.(1982)._- «Fatty Acid Changes in Hibiscus Esculentus Tissues During Growth".-Phytochemistry, 21, 565-568.

10. Christie, W. (1973)._-Lipid Analysis».-First Edn., Pergamon Press Oxford New York Toronto and Sydney, 87-96.

11. Peterson, B., Podlaha, O. and Toregard, B. (1981).«HPLC Separation of Natural Oil Triglycerides into Fractions with the Same Carbon Number and Numbers of Double Bonds".-JAOCS, 58, 1005-1009.

12. Gillatt, P. and Rossell, J. B. (1992)._-Oils and Fats Research at Leatherhead Food RA".-Inform, 3, 586-590.

13. Et-Mallah, M. H., Murui, T. and El-Shami, S. (1994).«Detailed Studies on Seed Oil of Salicornia SOS-7 Cultivated at the Egyptian Border of Red Sea"-Grasas y Aceites, 54, 385-389.

14. Murui, T. and Wanaka, K. (1993)._- «Measurement of Sterylglycosides by HPLC with 1-anthroylnitrile Derivatives".-Biosci. Biotech Biochem, 57, 614-617.

15. Budowski, P. and Sklan, D. in Vergroesen, A. J. and Crawford, M. eds. (1989). - «The Role of Fats in Human Nutrition».-Academic Press, New York, 363.

16. El-Mallah, M. H., Murui, T. and El-Shami, S.- «New Trends in Determining Oil Authenticity of Corn Oil».-Accepted for publication in Grasas y Aceites, in press.

17. Minar Mahmoud, M. Hassanein. (1996).— «Studies on Biochemical Changes in Lipids of Some Maturing and Germinating Oil Seeds".- Submitted for the Degree of $\mathrm{Ph}$. D., University of Ain Shams, Faculty of Science, Cairo, Egypt.

18. Adel Gabr Abd El-Razek. (1998).— «Studies on Chemical Composition of Some Vegetable Oil Admixtures". - Submitted for the Degree of M. Sc., Cairo University, Faculty of Agriculture, Cairo, Egypt. 